\title{
Por uma interpretação humanista da relação entre lugar e mobilidade
}

Jean Lucas da Silva Brum

UERJ

p. $102-119$

revista

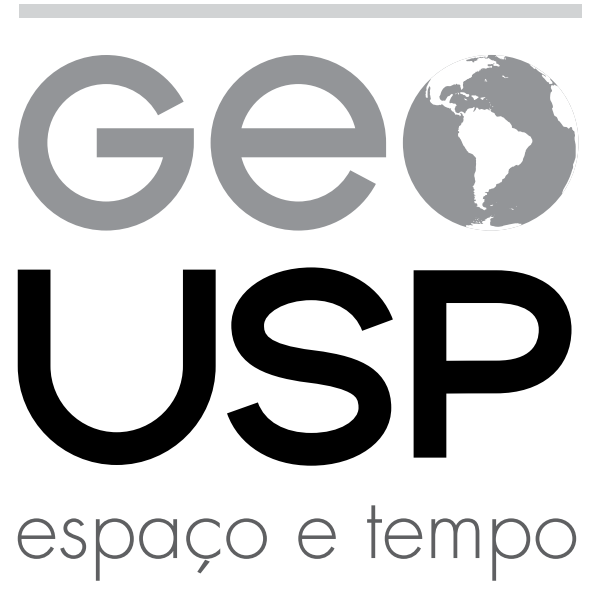

Volume $21 \cdot n^{\circ} 1(2017)$

ISSN 2179-0892
Como citar este artigo:

BRUM, J. L. S. Por uma interpretação humanista da relação entre lugar e mobilidade. Geousp - Espaço e Tempo (Online), v. 21, n. 1, p. 102-119, abril. 2017. ISSN 2179-0892.

Disponível em: $<$ http://www.revistas.usp.br/geousp/ article/view/115023 > . doi: 10.11606/issn.2179-0892. geousp.2017.115023.

\section{(c) $(1) \Theta$}

Este artigo está licenciado sob a Creative Commons Attribution 4.0 License. 


\title{
Por uma interpretação humanista da relação entre lugar e mobilidade
}

\section{Resumo}

Este ensaio apresenta uma reflexão crítica sobre a construção de sentidos de lugar pela prática da mobilidade, à luz de um olhar humanista-cultural. Limitamo-nos a construir um debate essencialmente teórico, baseando nas principais referências sobre lugar no entendimento humanista em geografia. Diferentemente do que apontam muitos geógrafos, acreditamos que a perspectiva humanista não exclui o papel da mobilidade na produção dos lugares. Muito embora o termo lugar seja um dos principais conceitos em geografia, o debate sobre sua definição ainda é escasso, sobretudo no que tange à relação entre lugar e mobilidade. Com este trabalho, pretendemos enriquecer a discussão em torno do conceito de lugar e sua importância na interpretação geográfica.

Palavras-chave: Lugar. Tempo. Mobilidade. Geografia humanista. Dança-do-lugar.

\section{Toward a humanist interpretation of the relation between place and mobility}

\begin{abstract}
This essay aims produce a critical reflection about the construction of senses of place through mobility practice in the light of a humanistic-cultural look. We limit ourselves to building an theoretical debate, based on the main references in discussions of place in the humanist geography. Unlike what many geographers have been pointing, we believe that the humanist perspective does not exclude the central role of mobility in the production of places. Although the term "place" presents itself as one of the main concepts in geography, the debate around its conceptualization is still scarce, especially regarding the relationship between place and mobility. We intend with this essay enrich the discussions around the concept of place and its importance in the geographical interpretation.
\end{abstract}

Keywords: Place. Time. Mobility. Humanist Geography. Place-ballet. 


\section{Palavras iniciais}

Lugar sempre foi um conceito de destaque em geografia, ainda que por um longo tempo as atenções em defini-lo claramente tenham permanecido em segundo plano nos debates dessa ciência (Holzer, 2003). Contudo, a partir da década de 1970, o processo de renovação epistemológica vivenciado pela geografia colocou em pauta novas questões e perspectivas de pensar esta ciência, o que refletiu a maneira de se trabalhar o conceito de lugar.

Muito do que se entende hoje pelo conceito de lugar em geografia deve-se aos esforços da geografia humanista. Tal corrente do pensamento geográfico se dedica à compreensão do homem em um envolvimento mais profundo com o mundo da vida, vislumbrando o papel dos simbolismos, sentimentos, valores e experiências nos elos humanos com o espaço (Tuan, 1985). Influenciados em larga escala pelas noções de "mundo vivido" e "habitar", importadas do método fenomenológico, os geógrafos humanistas buscaram na ressignificação do termo lugar um conceito que viabilizasse a construção de uma "nova" perspectiva em geografia (Holzer, 2012). O termo "lugar" se tornou o principal elemento de identificação do movimento humanista, sendo alçado como conceito chave da geografia (Holzer, 2012).

Dessa maneira, lugar passou a ser interpretado como um centro de significados, qualquer porção do espaço que tenha valor para um indivíduo ou grupo, ponto de referência simbólicoexistencial para as pessoas que desenvolvem uma relação de pertença ao lugar (Tuan, 1975a, 2011, 2013; Relph, 1976). Se por um lado descortina-se o espaço, domínio da liberdade e do movimento, por outro lado, a partir do olhar humanista, o lugar representaria um refúgio familiar, um ponto de apoio e estabilidade, um repositório de memórias e afetos (Mello, 1990, 1991), portanto, pausa no movimento (Tuan, 2013).

Alguns geógrafos, contudo, passaram a acusar a noção humanista de lugar como estática e excludente, enfatizando o lugar como um refúgio essencialmente nostálgico e eterno, e, portanto, incapaz de dar conta das dinâmicas impostas pelo capitalismo global, do incremento de fluxos e redes de pessoas e informações que caracterizam o mundo atual (Relph, 2012). Em geografia passou-se a questionar, portanto, a necessidade de pensar um conceito de lugar que não excluísse as "novas" formas de deslocamento humano, características desta atual fase de compressão tempo-espaço, inserido em um contexto marcado pelo multiculturalismo, pela fluidez, pela fragmentação e conectividade física e virtual (Marandola Jr., 2012).

Destacamos, no entanto, que longe de ser estático, como muitos geógrafos acusam, a ideia de lugar na geografia humanista é dinâmica, uma vez que se refere a nossa própria existência (Marandola Jr., 2012). A afirmação de Tuan (2013, p. 169), destacando o lugar como "pausa no movimento", de início pode parecer simplista, no entanto, esconde a complexidade em torno da qual a experiência de espaço, tempo, lugar e movimento se encontra estruturada.

O que pretendemos neste trabalho é justamente um mergulho teórico na perspectiva humanista de lugar, buscando clarificar como os geógrafos desta corrente articulam a ideia de mobilidade, entendida como o deslocamento humano no/com o espaço, e de que maneira esta prática atua na experiência de lugar. Para isto, procuramos recorrer aos debates em torno da conceituação de lugar em geografia e sua relação com a prática espacial da mobilidade, percorrendo bibliografias diversas, a fim de produzir uma reflexão crítica a respeito dos discursos 
por trás da construção teórica do conceito humanista de lugar. Dessa maneira, este trabalho, de natureza essencialmente teórica, tem como propósito contribuir para um debate epistemológico em torno da construção teórica do conceito de lugar e sua relação com a mobilidade.

\section{A perspectiva experiencial de lugar}

$O$ interesse da geografia acerca da noção de lugar, de fato, não representa um esforço propriamente recente. No entanto, é apenas a partir da década de setenta do século XX, com a emergência da geografia humanista, que o conceito lugar irá ganhar destaque nas discussões de caráter teórico, sendo ressignificado e desvinculado de uma perspectiva essencialmente locacional, dominante até aquele momento.

Surgida na década de setenta, a geografia humanista emerge em um contexto de intensos debates sobre o caráter epistemológico da ciência geográfica, podendo ser caracterizada como uma crítica radical ao positivismo e neopositivismo em geografia (Mello, 1990). Preocupados com uma redução mecanicista do papel do homem na construção do espaço geográfico operada pelas geografias de tradição neopositivista, alguns geógrafos se posicionaram criticamente contra uma "geografia sem homens", buscando em outros aportes "respostas para suas angústias e caminhos para o rompimento com o positivismo e o neopositivismo predominantes na ciência geográfica" (Mello, 1990, p. 92).

Foi na descoberta das chamadas "filosofias do significado", das quais a fenomenologia, a hermenêutica, o existencialismo e o idealismo são fontes, que os geógrafos preocupados com os aspectos subjetivos da espacialidade encontraram um caminho possível para a construção de um movimento que observasse nos elos existenciais do homem com o espaço o alicerce da compreensão geográfica (Mello, 1990).

Os geógrafos humanistas buscaram romper com a objetividade das análises centradas nas perspectivas cientificistas, para eleger a inextricável relação humana com o mundo, revestida de uma sorte de simbolismos, sentimentos e valores, como foco de atenção dos estudos geográficos. Segundo Buttimer (1985), o reducionismo científico, com a métrica estéril da matemática ou da física, não seria capaz de captar a beleza, a fragrância e o ritmo dos lugares, cabendo, portanto, à geografia humanista a tarefa de recuperar o sentido poético do envolvimento do homem com o mundo.

Inspirados pelos aportes das filosofias do significado, os geógrafos humanistas, interessados em descortinar a natureza geográfica em termos de uma indissociabilidade entre o ser e o mundo, irão alçar o lugar como um elemento essencial da existência humana (Holzer, 1999). Nesse sentido, Relph (1976, p. 1) argumenta: "ser humano é viver em um mundo cercado de lugares significativos: ser humano é ter e conhecer seu lugar". Mais do que simples pontos fixados em um mapa, o lugar, a partir da perspectiva humanista, se assume como experiência do mundo vivido (Buttimer, 1985). Por meio do lugar "nos identificamos, ou nos lembramos, construindo assim a base de nossa experiência do mundo" (Marandola Jr., 2012, p. 228). Nesse horizonte, a relação dialética homem-lugar é erigida como fundamento da existência humana situada geograficamente, como expressa por Casey (2001, p. 684): "Não há lugar sem self não há self sem lugar". Na compreensão humanista, se sentir ligado e enraizado a um lugar é uma 
importante necessidade humana (Relph, 1976). Esse pensamento orienta a reflexão de que as pessoas são os lugares que vivem e os lugares são, também, as suas pessoas, de modo que na experiência de mundo não há uma separação entre essas duas realidades (Relph, 1976). Portanto, o significado básico de lugar não advém simplesmente de sua localização, mas sim da relação experiencial que se estabelece entre os indivíduos e o mundo vivido, configurando-se, desse modo, enquanto um centro edificador da existência humana.

Nesse entendimento, essa concepção existencial de lugar na perspectiva humanista foi influenciada em larga escala pelo trabalho do geógrafo francês Eric Dardel (Holzer, 2012). Em sua obra chave, O homem e a terra: a natureza da realidade geográfica (2011), ${ }^{1}$ publicada originalmente em 1952 e praticamente negligenciada pela geografia até a década de setenta, quando é resgatada pelos autores da vertente humanista, Dardel procura explorar a relação ontológica homem-Terra, considerando o lugar como ponto de partida da experiência geográfica. Para Dardel (2011, p. 41), antes “de toda escolha, existe esse 'lugar' que não pudemos escolher, onde ocorre a 'fundação' de nossa existência terrestre e de nossa condição humana”, precisamos do lugar para estabelecer nossa existência. É do lugar, base de nossa existência, que tomamos consciência do mundo ao redor e vamos ao seu encontro (Dardel, 2011). Apesar de permanecer por um longo tempo esquecido, o trabalho de Dardel (2011) destaca-se como uma importante referência para a definição de lugar proposta pelos geógrafos humanistas.

A partir desta perspectiva, a geografia humanista redimensiona o lugar como categorial matricial do entendimento geográfico (Mello, 1990), compreendendo-o como um centro de significados construído a partir da experiência humana em seu contínuo envolvimento com o mundo (Relph, 1976, 1997, 2012; Tuan, 1975a, 2011, 2013). Nas palavras de Mello (1990, p. 102) "o lugar é recortado emocionalmente nas experiências cotidianas". Assim, "o que começa como espaço indiferenciado transforma-se em lugar à medida que conhecemos melhor e o dotamos de valor" (Tuan, 2013, p. 14).

Nesseregistro, o "lugaréum centro de açãoe intenção, ele éumfocoondenós experienciamos os eventos significativos da nossa existência" (Relph, 1976, p. 42). Resumidamente, podemos traduzir a noção de lugar como "qualquer localidade que tenha significado para uma pessoa ou um grupo de pessoas" (Tuan, 2011, p. 8). Os lugares são centros aos quais as pessoas atribuem valor em sua experiência de ser-estar no mundo (Tuan, 2013). Esses lugares são centrais tanto por atraírem usuários e irradiarem ideias e significados (Mello, 1995), quanto por seu papel fundamental na estruturação de mundos vividos, configurando-se como pontos articuladores da experiência cotidiana e de sua abertura para o mundo (Buttimer, 1985; Relph, 2012). Por serem focos de significados, os lugares carregam em si "poesia, emoção, sensação de paz e segurança dos indivíduos que estão entre os seus" (Mello, 1990, p. 102), sendo, portanto, compreendidos por uma relação dialética de pertencimento entre as pessoas e seus lugares.

Nas páginas iniciais da obra Espaço e Lugar, o geógrafo Yi-Fu Tuan defende que lugar pode ser entendido como segurança, se opondo ao espaço, este, domínio da liberdade (Tuan,

1 Do original francês L'homme et la terre: nature de La réalité geographique (1952). 
2013). Nas palavras do próprio autor, "a partir da segurança e estabilidade do lugar estamos cientes da amplidão, da liberdade e da ameaça do espaço" (Tuan, 2013, p. 14). Por meio da vivência, as pessoas constroem vínculos profundos com os lugares, de modo que familiaridade e enraizamento integram parte da experiência de lugar (Tuan, 2013). Esta mesma conotação é apresentada por Relph, quando este argumenta que "possuir raízes em um lugar é ter um porto seguro a partir do qual podemos olhar para fora sobre o mundo" (Relph, 1976, p. 38). Com efeito, essa perspectiva guiou muitos autores a considerar o lugar como ponto de apoio onde é possível encontrar segurança existencial e um "porto seguro" onde se pode ancorar um sentido de Ser, sendo, em vista disso, concebido como um ninho ou concha protetora, em uma relação mútua de pertencimento (Mello, 1990; Oliveira, 2012; Tuan, 2011, 2013).

Contudo, cabe considerar que nem todos os lugares são experienciados exclusivamente como pura e eterna afeição na perspectiva humanista. Como pontua Tuan (1975b), as atitudes humanas para com o lugar não podem ser lidas de maneira estritamente objetiva, de modo que os desejos e atos das pessoas são sempre confusos, marcados pela ambivalência e/ou ambiguidade. Isto posto, para ser alçado à categoria de lugar, "o local não precisa ser [necessariamente] investido de carinho e sim ser apenas um ponto de significação" (Mello, 1990, p. 105). Segundo Relph (1979), os lugares que conhecemos e nos sentimos envolvidos podem ser tanto aqueles aos quais tenhamos profunda afeição, quanto os quais despertam, em certa medida, nosso desgosto, de modo que "conhecer um lugar é desenvolver um sentimento topofílico ou topofóbico" (Oliveira, 2012, p. 12).

Nesse caminho, o lugar não evoca apenas sentidos positivos de afeição e bem querência. Os lugares são, também, foco de tensões diárias, de lutas, de desavenças e de desejos de fuga. O significado mais original de lugar vem de sua ligação intrínseca com a existência humana, abarcando, em um mesmo sentido, movimentos recíprocos e contraditórios: aqueles que nos envolvem ao lar e nos levam ao aprofundamento de nossas raízes e aqueles que nos empurram em busca de horizontes de alcance, ou seja, lugares que estão além de nosso alcance imediato, que ansiamos conhecer e nos aventurar, nos orientando para fora de nosso lar (Buttimer, 2015). Como foco de intencionalidades (Relph, 1976), as pessoas estão irremediavelmente vinculadas aos lugares, queiram elas ou não, de modo que é extremamente "difícil decidir de antemão em que tipo de ambiente você deseja viver, avaliar a qualidade dos lugares e selecionar o melhor, de acordo com um critério definido racionalmente" (Relph, 1979, p. 17). Como centro de significados, o lugar remonta a complexidade e ambiguidade de atitudes e formas como o mundo é experienciado pelas pessoas. $O$ que pretendo com isso não é negar que o lugar se exprime como fonte de enraizamento, familiaridade, segurança e pertencimento nos vínculos humanos em sua existência mundana, mas sim, que a experiência de lugar engloba emoções e sentimentos complexos, por vezes, contraditórios.

\section{Elementos para pensar a mobilidade}

Nas últimas décadas, as ciências humanas têm presenciado a emergência de um profundo interesse em torno da temática da mobilidade. Essa compreensão vem acompanhada do anúncio de um "novo paradigma da mobilidade" (Sheller; Urry, 2006), apontando a existência 
de novíssimas formas de deslocamento, do aumento de fluxos, de um alargamento das redes e conexões, levando a repensar o papel da mobilidade na estruturação e experiência do mundo contemporâneo (Cresswell, 2006). Em geografia, alguns autores defendem a mobilidade como uma das principais marcas da modernidade líquida, expressão amplamente divulgada pelo sociólogo Zygmunt Bauman (2001) para designar o atual estágio em que se encontra a sociedade capitalista global, conferindo ao espaço uma maior fluidez e interconexão frente à fixidez que a modernidade sólida buscou estabelecer (Marandola Jr., 2014).

Grande parte do interesse sobre a mobilidade como símbolo da sociedade capitalista contemporânea tem como pano de fundo os desenvolvimentos tecnológicos gestados nas últimas décadas do século XX (Cresswell, 2010). O processo de globalização foi responsável por promover novos arranjos espaciais que modificaram e ao mesmo tempo se baseiam na mobilidade (Rosas; Hogan, 2009). A disseminação de formas de transporte mais rápidas e eficientes produziram um verdadeiro rearranjo espacial (Moreira, 2010) com vias a promover a realização mais eficaz dos deslocamentos. Ao lado disso, a expansão desenfreada de tecnologias de comunicação, permitindo o acesso quase instantâneo a informações produzidas a centenas de quilômetros de distância ao alcance de um simples "clique", a exemplo da internet, instituiu uma lógica de aceleração das relações sociais, em que velocidade e instantaneidade se tornaram palavras de ordem (Virilio, 1984). Presencia-se, portanto, a intensificação do processo de compressão tempo-espaço, assim como destacado por Harvey (1992), expresso pela aceleração do tempo e da redução virtual das distâncias.

Entretanto, ao mesmo tempo em que conecta e encurta distâncias, a mobilidade pode engendrar, em outras escalas, a desconexão e fragmentação territorial (Haesbaert, 2004). As formas e os recursos capazes de promover o deslocamento, seja ele físico ou virtual, estão distribuídos de maneira desigual no espaço, de modo que, enquanto algumas pessoas se estão inseridas nos circuitos globais de deslocamento, outras, devido à falta de recursos ou por terem seu acesso negado, permanecem restritas territorialmente (Sheller; Urry, 2006). Tendo isto em vista, as atuais formas de mobilidade e conectividade podem produzir geografias de exclusão, de desconexão, de desigualdade e de imobilidade (Merriman, 2009). A esse respeito, Bauman (1999) destaca:

Junto com as dimensões planetárias dos negócios, das finanças, do comércio e do fluxo de informação, é colocado em movimento um processo "localizador", de fixação no espaço. [...] O que para alguns parece globalização, para outros significa localização; o que para alguns é sinalização de liberdade, para muitos outros é um destino indesejado e cruel. A mobilidade galga ao mais alto nível entre os valores cobiçados - e a liberdade de movimentos, uma mercadoria sempre escassa e distribuída de forma desigual, logo se torna o principal fator estratificador de nossos tardios tempos modernos ou pós-modernos (Bauman, 1999, p. 7).

Dessa forma, apresenta-se a mobilidade como elemento chave para compreender as 
relações entre as pessoas e os lugares no mundo contemporâneo, seja pela construção de fluxos e conexões em diversos contextos e escalas, colocando as pessoas em contato com uma multiplicidade lugares, ou pela desconexão e fragmentação, criando aglomerados de exclusão (Haesbaert, 2004), zonas periféricas a margem dos circuitos de movimento global.

Num nível básico, a mobilidade está relacionada à qualidade do que pode se mover. A ideia de movimento é central na compreensão da mobilidade, não significando, contudo, que esses termos sejam sinônimos. Segundo Cresswell (2006), o termo movimento pode ser caracterizado como uma categoria geral, o deslocamento de um objeto qualquer em um espaço-tempo abstrato, algo quantificável, sem considerar os tipos, as estratégias e as implicações desse movimento. A mobilidade, por seu turno, se apresentaria como sendo mais restrita, caracterizando-se como uma prática social. Segundo Levy (2001, p. 7):

Pode-se definir a mobilidade como a relação social ligada à mudança de lugar, isto é, como o conjunto de modalidades pelas quais os membros de uma sociedade tratam a possibilidade de eles próprios ou outros ocuparem sucessivamente vários lugares. Por essa definição, excluímos duas outras opções: aquela que reduziria a mobilidade ao mero deslocamento [...], eliminando assim as suas dimensões ideais e virtuais, e aquelas que dariam um sentido muito geral deste termo, jogando com metáforas (tal como mobilidade social) ou com extensões incontroladas (a comunicação, por exemplo).

Nessa compreensão, as práticas que levam a construção da mobilidade não ocorrem em um espaço-tempo abstrato, ao contrário, elas se realizam em um espaço-tempo social, sendo, portanto, elemento de produção desse espaço-tempo social por meio de uma relação dialética (Cresswell, 2006). Como produto social, a mobilidade "tem um papel fundamental na estruturação do cotidiano das pessoas, compondo sua própria essência" (Marandola Jr., 2014, p. 104). De tal forma, estar inserido geograficamente no mundo é permanecer em constante movimento, por seu turno, a própria mobilidade se torna parte desta vivência geográfica.

Cresswell $(2006,2010)$ aponta a existência de três elementos na construção social da mobilidade. Primeiro, ela envolve movimento físico. Nesse sentido, a mobilidade é considerada como fato empírico e mensurável: no cotidiano, objetos e pessoas permanecem em constante movimento entre um ponto e outro. Esta perspectiva aproxima a ideia de mobilidade a de movimento. Segundo, como uma prática social, ela envolve significado. Assim, mais do que um mero deslocamento abstrato, a mobilidade está envolta de simbolismo. Desta maneira, há diversos sentidos de mobilidade, construídos a partir das práticas cotidianas ou mesmo pele representações midiáticas como: liberdade, transgressão, aventura, ou mesmo sacralidade, perigo e tédio. Terceiro, ela é praticada e experienciada, tanto socialmente, quanto corporalmente. A mobilidade, nesse âmbito, é uma forma de estar no mundo, uma forma de agir e situar-se mundanamente, sendo, portanto, essencial na compreensão da existência humana e em sua experiência de mundo vivido. 
Cabe destacar que a mobilidade não se realiza uniformemente em um espaço contínuo (Cresswell, 2010). Ao invés disso, ela é "canalizada", isto é, a mobilidade se realiza por meio de rotas e caminhos, ligando um lugar a outro. A mobilidade demanda a existência de estruturas capazes de sustentá-la, como, por exemplo, estradas, pontes, trilhos ou mesmo o ar e a água (Sheller; Urry, 2006; Cresswell; Merriman, 2008). Essas rotas têm sua própria métrica, sendo responsáveis por direcionar ou limitar a mobilidade. Assim, tais estruturas caracterizam-se como contexto e agentes na produção da mobilidade (Cresswell; Merriman, 2008).

Ao lado do exposto, os pontos de parada ou descanso são igualmente importantes. São lugares onde o movimento é reduzido, pausado ou mesmo interrompido: aeroportos, estações rodoviárias, portos, entre outros (Sheller, 2011). Esses pontos podem ser caracterizados como "nós", conectando diversas localidades por meio de um complexo sistema de fluxos (Sheller; Urry, 2006). De tal maneira, existe certo grau de imobilidade indispensável no exercício da própria mobilidade, fazendo com que esta prática integre fixos e fluxos. Contudo, mais do que simples estruturas materiais que permitem o deslocamento, em meio à vivência humana, estas estruturas e locais são envolvidos de carga simbólica. Nesse âmbito, o mundo vivido das pessoas é composto tanto de pontos fixos como, por exemplo, o local de residência, de trabalho, de lazer, entre outros, quanto de movimentos e itinerários percorridos cotidianamente, esporadicamente ou mesmo de maneira excepcional (Marandola Jr., 2014). Essa complexa teia de lugares, itinerários e movimentos, quando revestidos de significados e valores edificados pela experiência, compõe o mundo vivido dos indivíduos, fazendo emergir lugares erigidos por meio do movimento.

Diante do exposto, a mobilidade é mais do que simplesmente o deslocamento de algum objeto ou pessoa de um ponto A para um ponto B, ela abarca materialidade, significados, experiência e corporeidade (Cresswell, 2006, 2010), e uma gama de aspectos que são próprios da vivência humana. Desta maneira, a mobilidade tem um papel central na compreensão do envolvimento cotidiano das pessoas com os lugares e na experiência de mundo vivido.

\section{Lugar, tempo e mobilidade}

Tradicionalmente, o conceito lugar foi considerado essencialmente estático, por vezes se confundindo com a própria ideia de localização. Tal concepção, conferindo maior atenção a noções como enraizamento, fronteiras e identidades singulares, foi responsável por mitigar o dinamismo imposto pela mobilidade na construção de sentidos de lugar (Cresswell, 2009). De fato, alguns trabalhos de teor humanista enfatizam a compreensão da mobilidade contemporânea como um empecilho à criação de um sentido profundo de lugar. A esse respeito, apenas a título de exemplo, Yi-Fu Tuan, um dos expoentes do aporte humanístico, argumenta que, para o homem moderno, comprometido com variados fluxos e movimentos, "a relação entre mobilidade e lugar pode ser mais complicada" (Tuan, 2011, p. 16), conforme ele se move rapidamente entre muitos lugares, "estes tendem a perder suas características especiais" (Tuan, 2011, p. 16). Segundo Tuan (2011, p. 12), "o homem secular moderno está no 'caminho', é o 'povo da estrada' [...]. Eles são pessoas sem raízes, livres de vínculos com o lugar, ou com familiares".

Nessa perspectiva, os espaços que promovem a mobilidade, bem como o próprio 
movimento realizado, seriam responsáveis por uma diluição dos lugares, fazendo emergir um senso de "não lugaridade" ou de "deslugaridade", apontando um fim dos lugares legítimos como marca dos tempos hodiernos. Esse entendimento pode ser observado em intelectuais de diferentes disciplinas ou mesmo matrizes teóricas, entre esses, destacam-se os trabalhos do geógrafo Edward Relph e do antropólogo Marc Augé.

Influenciado em grande medida pela fenomenologia heideggeriana, Relph aponta que atitudes inautênticas para com o lugar, a exemplo de atitudes mediadas, padronizadas, artificiais, simuladas ou mesmo modismos, podem gerar um sentido de "deslugaridade" (placeless) (Relph, 1976). Nesse horizonte, o autor indica que a intensa mobilidade contemporânea constitui-se como um elemento na criação de "lugares-sem-lugaridade" (placelessness), quais sejam: superfícies padronizadas e uniformes, simbolicamente enfraquecidas, que pouco ou nada sugerem do contexto que se estabelecem e das pessoas que nelas vivem (Relph, 1976, 2012). Entre muitas evidências levantadas, o autor defende que as vias de transporte, possibilitando o deslocamento vertiginoso entre diversas localidades, representam esse espírito de "deslugaridade" (placeless). Com efeito, para Relph (1976), estradas, ferrovias, aeroportos e outras vias de circulação, não são apenas lugares-sem-lugaridade em seu próprio direito, mas, ao possibilitar o movimento em massa das pessoas com suas modas e hábitos, incentivam a disseminação dos lugares-semlugaridade para bem além de sua escala imediata.

Paralelamente às ideias de Relph, muito embora um não recorra ao outro, o antropólogo Marc Augé aponta a proliferação de "nãolugares" (non-lieux) como marca da "supermodernidade" (surmodernité), termo utilizado pelo autor para se referir ao atual estágio em que se encontram as sociedades capitalistas globalizadas. Para Augé (1994), os não lugares seriam representados por "espaços de circulação, comunicação e consumo, onde a solidão coexiste sem criar algum laço social" (Augé, 1996, p. 178), tornando-se, em vista disto, uma contraposição ao que o autor propõe chamar de "lugares antropológicos", qual seja uma construção concreta e simbólica do espaço, a qual os indivíduos se reconhecem por laços relacionais, identitários e históricos (Augé, 1994). Como exemplos de não lugares, o autor cita as vias de circulação (vias aéreas, ferrovias, rodovias), os meios de transporte (aviões, trens, ônibus, carros), os aeroportos, as estações férreas e aeroespaciais, as estandartizadas cadeias de hotéis, os parques temáticos, os grandes centros de consumo, como os shopping centers, e toda uma sorte de superfícies funcionais e padronizadas fabricadas em massa, promovendo a circulação intensa e o anonimato, na qual o indivíduo desenvolve uma relação contratual, dialogando com textos e imagens (Augé, 1994, 1996).

Vale ressaltar que quando Augé (1994) propõe a existência de não lugares como expressão da "supermodernidade", o faz contrapondo com o que considera "lugares antropológicos", que, apesar de sua dimensão espacial, se assume a partir de um caráter eminentemente simbólico, ou seja, aqueles aspectos ligados a construção cultural de determinado grupo social. Por sua vez, a consideração de lugares-sem-lugaridade, proposta por Relph, emerge como face da própria experiência existencial e corpórea do espaço, não significando, portanto, uma contraposição direta ao lugar. Assim, enquanto para o primeiro, os não lugares expressariam novíssimas formas desenraizadas, efêmeras, fluídas, de viver/experienciar o mundo, revelando 
um menor comprometimento simbólico para com os lugares "antropológicos", para o segundo, os lugares-sem-lugaridade são o resultado da tensão nas formas de experienciar o mundo em sua geograficidade.

Muito embora cada autor escreva em um período específico e percorra caminhos distintos em suas considerações a respeito da experiência de mundo, em ambos é possível identificar o discurso que aponta a mobilidade como possível empecilho a fruição de um profundo ou autêntico senso de lugar.

Independente dessas considerações enfatizarem a existência de "não lugares" ou de "lugares-sem-lugaridade" (placelessness) como expressões dos intensos deslocamentos humanos no mundo contemporâneo, acredito na possibilidade de pensar a mobilidade como um elemento indispensável na prática, experiência e vivência de lugar. De igual maneira, ainda que alguns trabalhos de inspiração humanista corroborem a perspectiva discutida anteriormente, isso não significa dizer que os geógrafos desta corrente abandonam completamente o papel da mobilidade no processo criativo dos lugares. Nesse registro, Tuan apresenta uma importante contribuição sobre a relação entre espaço, movimento e lugar na perspectiva humanista.

Ao relacionar os conceitos de espaço e lugar, Tuan (2011, p. 8) escreve: "o espaço não é uma ideia, é um conjunto complexo de ideias [...] o lugar é um espaço estruturado". O espaço, nessa interpretação, seria o domínio do instável, da mudança, do desconhecido. Enquanto o lugar tem uma existência estável, conhecido a partir das experiências íntimas que temos com o mundo. $\bigcirc$ autor resume suas elucubrações sublinhando que "o lugar é a segurança e o espaço é a liberdade" (Tuan, 2013, p. 11). O espaço como liberdade, estaria associado à ideia de movimento, capaz de produzir mudança e instabilidade. Por seu turno, "o lugar é pausa no movimento [...] A pausa permite que uma localidade se torne um centro reconhecido de valor" (Tuan, 2013, p. 169). Nesse contexto, Tuan destaca: "olugar é um mundo de significado organizado. É essencialmente um conceito estático. Se vivêssemos o mundo como um processo, em constante mudança, não seríamos capazes de desenvolver nenhum sentido de lugar" (Tuan, 2013, p. 219).

Tal afirmação foi amplamente criticada no cenário acadêmico. Muitos geógrafos passaram a acusar a concepção humanista de lugar como essencialmente estática e imutável, não levando em consideração a mobilidade e o dinamismo imposto na criação dos lugares. Entretanto, a pausa, como referida pelo autor, não deve ser compreendida de forma literal, como se representasse uma permanência fixada no espaço, mas sim em termos intersubjetivos na relação tempo-espaço, como momentos de estabilidade na experienciação espacial. Nessa perspectiva, a pausa mencionada por Tuan remonta a noção fenomenológica de habitar, indicando que o real envolvimento com o mundo demanda um "de-morar-se", por um permanecer que é próprio do ser-no-mundo, não em um sentido cronológico de tempo, mas em um sentido intersubjetivo, expresso pela vinculação com o lugar (Marandola Jr., 2014). Para Relph (2012), a noção de habitar é aquela que encontra maior consonância com a ideia de lugar como explicitada pelo entendimento humanista, revelando que "estar na terra significa morar, relacionar-se com lugar por meio da existência [...] ter experiências de lugar que são transcendentais e inexplicáveis" (Relph, 2012, p. 30). A "pausa", relacionada à compreensão fenomenológica, nãoé simplesmente a interrupção de um deslocamento físico, mas sim o envolvimento do homem com o mundo por 
meio da experiência de tempo e espaço. Nesse sentido, em algumas circunstâncias, mesmo no movimento é possível experienciar o lugar como pausa, na medida em que a pausa se refere muito mais a ideia de vinculação com o mundo do que de uma ausência ou interrupção do movimento.

Para elucidar a ideia anteriormente explicitada, Tuan recorre ao exemplo de grupos nômades. O autor observa:

mundo do nômade consiste em lugares conectados por um caminho. Os nômades que estão frequentemente se deslocando, têm um sentido intenso de lugar? É bem provável [...] Para os nômades, as exigências cíclicas da vida produzem uma sensação de lugar em duas escalas: os acampamentos e o território muito maior no qual se movimentam (Tuan, 2013, p. 221).

Nesse contexto, ainda que apresentem um estilo de vida baseado no constante movimento, para alguns grupos nômades os caminhos percorridos e os acampamentos são elementos de referência espacial em sua experiência de mundo. De modo similar, alguns autores enfatizam que mesmo para o nômade existe certo grau de previsibilidade nos caminhos realizados, em sua maioria repetindo periodicamente os mesmos trajetos (Bonnemaison, 2012; Haesbaert, 2004). Em vista disto, longe de uma lógica de deslocamento aparentemente imprevisível e desordenada, os movimentos respeitariam uma ordem cíclica, caracterizando-se, portanto, como "pausa". Em outras palavras, por meio do controle dos fluxos e dos trajetos por um padrão determinado, os nômades podem ter uma profunda experiência de lugar sobre todo o perímetro percorrido (Bonnemaison, 2012). Dessa maneira, mesmo que a mobilidade represente um aspecto central na experiência de mundo dos nômades, os mesmos não são desprovidos de um sentido de lugar.

Muito embora Tuan use como exemplo os grupos nômades, essas considerações podem ser transpostas quando pensamos a construção do mundo cotidiano de outros grupos, como sociedades urbanas sedentárias. Os imperativos da vida cotidiana nas cidades conduzem as pessoas a um constante deslocamento, tais como entre a casa, o trabalho e os locais de compra e lazer, ou mesmo viagens de férias e descanso (Rosas; Hogan, 2009). Nesse caso, a experiência que uma pessoa tem sobre seu bairro ou cidade está, em certa medida, comprometida com os trajetos percorridos, a forma como o movimento é realizado e os locais que engendram esses movimentos. Assim, "pode-se considerar que uma cidade permite até certo ponto a cada citadino 'fabricar' a sua cidade" (Levy, 2001, p. 10), o seu "mundinho" ou mundo pessoal e que justamente a maneira como a mobilidade é empreendida constitui um instrumento decisivo nessa construção.

Evidentemente, quando se trata da experiência é muito difícil afirmar a existência de uma fórmula pronta e acabada que confirme este ou aquele aspecto da mobilidade como essencial na construção de lugar. Pode-se dizer então que cada indivíduo cria seu próprio mundo dentro de suas estratégias de mobilidade, um mundo dinâmico marcado pelo entrecruzamento de vários movimentos, velocidades e coreografias que impõem significado ao espaço (Seamon, 2013).

Ainda nessa discussão, Tuan $(2011,2013)$ ressalta a importância da experiência que se tem 
sobre o tempo na intricada relação entre lugar e movimento. Por mais que conceitualmente sejam tratados de maneira distinta, na experiência humana de mundo, tempo, lugar e movimento permanecem constantemente relacionados. Segundo Tuan (2011, 2013), é possível pensar ao menos três abordagens na relação entre lugar e tempo: tempo como movimento e lugar como pausa; afeição pelo lugar como função do tempo e lugar como lembrança de tempos passados. A primeira abordagem é aquela que mais se articula com a proposta que aqui procuro delinear.

De acordo com Tuan (2013), as pessoas adquirem um sentido de espaço e de tempo porque são capazes de se mover. Por sua vez, o movimento espacial poderia ser caracterizado, em termos de direção, como linear (quando segue em uma direção) ou circular (implicando repetição). Segundo esse autor, o movimento linear estaria relacionado a um sentido de tempo também linear. Para elucidar esta perspectiva, Tuan (2013) propõe simbolizar o fluxo temporal linear como uma flecha, destacando a existência de um ponto de partida, um caminho único a ser percorrido, e um destino a ser atingido. Nesse âmbito, movimento e tempo linear se encontrariam estruturados em torno de três categorias espaciais, quais sejam: o lar, a meta e os acampamentos ou paradas no caminho. Tuan (2013) assim resume: "o lar é o mundo estável a ser transcendido, a meta é o mundo estável a ser alcançado, e os acampamentos são paradas de descanso no caminho de um mundo para o outro" (Tuan, 2013, p. 220). Isto posto, o lar, a meta e os acampamentos, por emergirem como pausas no fluxo temporal contínuo podem ser caracterizados como lugares. Entretanto, grande parte dos deslocamentos rotineiros não são empreendimentos estruturados ao redor de pontos contrários. Como pontua Tuan (2013, p. 220), "a maioria dos movimentos completa um caminho mais ou menos circular, ou oscila para trás e para frente como um pêndulo [..] como resultado do uso habitual, o próprio caminho adquire uma densidade de significado e uma estabilidade que são traços característicos de lugar". Assim, como consequência do movimento cotidiano, o caminho percorrido, bem como os locais que propiciam o movimento, são interiorizados, ganhando contornos de lugar. Cabe considerar, nessa instância, que não apenas o meio físico (caminho e locais) de realização da mobilidade se verte em lugar, mas a própria prática da mobilidade espacial, como ato humano performatizado pelo corpo, também se apresenta como lugar; estar em constante movimento, deslocar-se, como experiência e sentido de se sentir ligado, pertencido ao um lar-lugar.

O geógrafo David Seamon, também ligado a tradição humanista, em muito contribuiu para a compreensão das relações estabelecidas entre lugar e mobilidade. A noção de "dançado-lugar" (place-ballet), apresentada por Seamon no final da década de 1970, em sua obra $A$ Geography of Lifeworld (1979), configura-se como um valioso instrumento na compreensão dos diversos movimentos, fluxos e itinerários que compõem o espaço geográfico. Seamon (1979) propõe um entendimento experiencial dos movimentos cotidianos, enfatizando o deslocamento humano como elemento fundamental na criação dos lugares, imprimindo a estes uma coreografia característica e única (Carvalho, 2006).

Reconhecendo a indissociabilidade entre as dimensões subjetivas e objetivas na realização dos movimentos, Seamon (1979) argumenta que a visão fenomenológica compreende os movimentos cotidianos como experiência, revelando, de tal modo, como eles ocorrem no seu 
próprio modo, com sua própria estrutura e dinâmica.

Nesse caminho, o autor vai buscar nas noções de "dança-do-corpo" e de "rotinas espaçotemporais" os elementos chave na composição do dança-do-lugar. Inspirado nos aportes da fenomenologia existencialista de Merleau-Ponty, Seamon (1979) irá argumentar que o corpo assume um caráter distintivo na experiência de mobilidade. Assim, para o autor, gestos, passos e movimentos que sustentam uma determinada tarefa ou meta conferem ao corpo um tipo de atuação inata, o que ele propõe chamar de "dança-do-corpo". Esta dança-do-corpo, no entanto, está sempre inscrita em um contexto espacial e temporal específico, e quando repetidos formam uma "rotina espaço-temporal". Quando as danças-do-corpo e as rotinas espaço-temporais se fundem em um meio ambiente que sustenta e tem como pilares essas ações, temos o que Seamon (1979) considera "dança-do-lugar": um espaço-ambiente dinâmico emergindo da "interação de muitas rotinas espaço-temporais e danças-do-corpo enraizadas no espaço" (Seamon, 1979, p. 56), experienciado pelo complexo de itinerários, passos e movimentos que constituem o lugar. $\mathrm{Na}$ experiência humana, portanto, espaço, tempo e lugar permaneceriam integrados em um eixo relacional das mobilidades do corpo. $\bigcirc$ lugar, compreendido sob essa perspectiva, pode ser considerado múltiplo e dinâmico, integrando várias "danças-do-lugar" na composição de um ambiente em constante movimento, incorporando as práticas e identidades dos indivíduos que dele participam.

O que o autor procura referenciar com essa noção é justamente o fato de que o lugar, como fenômeno experiencialmente construído, transcende a mera condição locacional. Tendo isso em vista, os lugares abarcam as interações entre os vários atores. Pensar, portanto, na experiência humana de espaço sob a perspectiva do dança-do-lugar é reconhecer que os movimentos cotidianos, realizados de maneira autoconsciente ou não, fazem parte da construção de lugar. Por meio de padrões habituais de encontro no tempo e no espaço, resultado do entrecruzar dos variados movimentos empreendidos individualmente, "uma área pode se tornar um lugar, dividido pelas pessoas que lá entram em contato espaço-temporal” (Seamon, 2013, p. 15). Para além disso, como já destacamos, mesmo a própria mobilidade, o movimento visto como prática social, pode ser alçada como lugar, em uma relação dialética mobilidade-lugar.

Na esteira dessa discussão, Buttimer $(1985,2015)$ sublinha que do comportamento humano diário emerge uma constante tensão entre os movimentos que levam ao envolvimento com o lar, criando profundos laços de enraizamento, proteção e cuidado, e aqueles que empurram em busca de horizontes de alcance orientados para fora do lar. Nessa trilha, "a reciprocidade vivida de descanso e movimento, território e horizontes de alcance, segurança e aventura" (Buttimer, 2015 , p. 8) surge como faceta dos ritmos do mundo vivido cotidiano. Isto posto, a experiência de lugar está comprometida com esta tensão entre forças estabilizantes e inovadoras, revelando o dinamismo no bojo da criação do lugar (Buttimer, 1985).

Como Relph (2012, p. 31) sentenciou, "lugar não é meramente aquilo que possui raízes, conhecer e ser conhecido no bairro; não é apenas a distinção e apreciação de fragmentos de geografia". A base do significado de lugar não se encontra em uma suposta essência locacional, mas sim, "se estende em suas ligações inextricáveis com o ser, com a nossa própria existência" (Relph, 2012, p. 31). Nesse contexto, Relph destaca: 
O lar, e na verdade todo lugar, não é delimitado por limites precisamente definidos, mas no sentido de ser o foco de intensas experiências, é ao mesmo tempo sem limites. Lugar é onde conflui a experiência cotidiana, e também como essa experiência se abre para o mundo (Relph, 2012, p. 29).

Em um mundo cada vez mais interconectado, fluído e móvel, a mobilidade não leva meramente a diluição ou destruição dos lugares autênticos. Pelo contrário, pode ser o efeito próprio de adensamento necessário a construção de um sentido de lugar, ou mesmo, o próprio sentido de lugar em si, em uma relação de coprodução lugar-mobilidade. Em seus deslocamentos, sejam eles rotineiros ou esporádicos, cada indivíduo carrega consigo um pouco de seu lar, levando parte de seu mundo circundante, seu mundo vivido, em seus trajetos (Marandola Jr., 2014). Essa experiência é capaz de tornar o todo indistinto percorrido, em outras palavras, um espaço qualquer, em lugar, recortado emocionalmente e dotado de intimidade. Dessa maneira, mais do que produtora de lugares-sem-lugaridade ou de não lugares, a mobilidade tem o potencial agregador na criação dos lugares.

\section{Considerações finais}

Vivemos num mundo que se movimenta em diferentes velocidades, escalas e distâncias. Os lugares a que sentimos pertencer não são apenas aqueles pontos fixos, localmente inscritos, mas também os que afloram nos fluxos, a partir de uma complexa rede ou teia formada por pontos, linhas e nós (Levy, 2001). Assim, "podemos nos sentir em casa em uma rodovia (linha) ou num supermercado (ponto), num trem (linha) ou num telefone (ponto)" (Levy, 2001, p. 19).

Procuramos demonstrar neste trabalho como a geografia humanista concebe o lugar e sua estreita relação com a prática espacial da mobilidade. Apontamos que, longe de ser um conceito puramente estático, como muitos autores fazem crer, a perspectiva humanista tem uma forma particular de considerar o papel dos deslocamentos na edificação de sentidos de lugar, compreendendo os elos existenciais que conectam os homens ao mundo. Ainda que alguns geógrafos de vertente humanista corroborem a visão de que a mobilidade tem um potencial desagregador, dificultando a fruição de um profundo sentido de lugar, apontar que todo o entendimento humanista se resume a essa consideração seria um equivoco. Nesse sentido, pela discussão do trabalho de autores como Tuan, Seamon, Relph e Buttimer, buscamos explorar que a ideia de lugar na geografia humanista é dinâmica, uma vez que se detém na existência e em experiências propriamente humanas.

Nesse caminho, acreditamos ter atingido nosso objetivo inicial: apresentar uma reflexão teórica que pudesse contribuir para o debate sobre a relação entre lugar e mobilidade na perspectiva da geografia. Contudo, destacamos a necessidade de se ampliar a discussão aqui levantada, buscando, tanto a partir de evidências empíricas, quanto de um maior esforço teórico, desvelar a complexa relação da produção de sentidos de lugar pelo movimento. 


\section{Referências}

AUGÉ, M. Por uma antropologia da mobilidade. Maceió: Edufal/Unesp, 2010.

. Paris and the ethnography of the contemporary world. In: SHERINGHAM, M.

(Ed.). Parisian fields. London: Reaktion, 1996. p. 175-181.

. Não lugares: introdução a uma antropologia da supermodernidade. Campinas, SP: Papirus, 1994.

BAUMAN, Z. Modernidade líquida. Rio de Janeiro: Zahar, 2001.

Globalização: as consequências humanas. Rio de Janeiro: Zahar, 1999.

BONNEMAISON, J.Viagememtornodoterritório. In: CORRÊA, R. L.; ROSENDAHL, Z. (Org.). Geografia cultural: uma antologia. v. I. Rio de Janeiro: Eduerj, 2012. p. 279-304.

BUTTIMER, A. Lar, horizontes de alcance e o sentido de lugar. Geograficidade, Niterói, RJ, v. 5, n. 1, p. 4-19, 2015.

Aprendendo o dinamismo do mundo vivido. In: CHRISTOFOLETTI, A. C. (Org.). Perspectivas da geografia. São Paulo: Difel, 1985. p. 165-193.

CARVALHO, R. O "balé do lugar" na cidade do Rio de Janeiro: a cultura como instrumento de resignificação espacial. In: CONGRESSO BRASILEIRO DE CIÊNCIAS DA COMUNICAÇÃO, 29., 2006, Brasília. Anais... Brasilia, 2006.

CASEY, E. Between Geography and Philosophy: the place-world? In: ASSOCIATION OF AMERICAN GEOGRAPHERS, 2001. Annals... v. 91, n. 4, 2001. p. 83-93.

CASTELLS, M. A galáxia da internet. Rio de Janeiro: Zahar, 2003.

CORREA, R. Trajetórias geográficas. Rio de Janeiro: Bertrand Brasil, 1997.

CRESSWELL, T. Towards a politics of mobility. Environment and Planning D: Society and Space, n. 28, p. 17-31, 2010.

Place. In: KITCHIN, R.; THRIFT, N. (Ed.). International Encyclopedia of Human Geography. v. 8. Amsterdam: Elsevier Science, 2009. p. 169-177

On the Move: Mobility in the Modern Western World. New York: Routledge, 
2006.

Place: a short introduction. Oxford: Blackwell, 2004.

Theorizing place. In: CRESSWELL, T.; GINETTE, V. (Ed.). Mobilizing Place, Placing Mobility. Amsterdam: Rodopi, 2002. p. 11-31.

CRESSWELL, T.; MERRIMAN, P. (Ed.). Geographies of Mobility: Practices, Spaces, Subjects. Aldershot: Ashgate, 2008.

DARDEL, E. O homem e a terra: natureza da realidade geográfica. São Paulo: Perspectiva, 2011.

L'homme et la terre: nature de la réalité geographique. Paris: PUF, 1952.

HAESBAERT. R. O mito da desterritorialização: do "fim dos territórios" à multiterritorialidade. Rio de Janeiro: Bertrand Brasil, 2004.

HARVEY, D. A condição pós-moderna: uma perspectiva sobre as origens da mudança social. São Paulo: Loyola, 1992.

HOLZER, W. A geografia humanista: uma revisão. In: CORRÊA, R. L.; ROSENDAHL, Z. (Org.). Geografia cultural: uma antologia. Rio de Janeiro: Eduerj, 2012. p. 165-178. v. 1.

O conceito de lugar na geografia cultural-humanista: uma contribuição para a geografia contemporânea. GEOgraphia, Niterói, RJ, v. 5, n. 10, p. 113-123, 2003.

. O lugar na geografia humanista. Território, Rio de Janeiro, v. IV, n. 7, p. 67-78, 1999.

A geografia humanista anglo-saxônica: de suas origens aos anos 1990. Revista Brasileira de Geografia, Rio de Janeiro, n. 55, p. 109-146, 1993.

LEVY, J. Os novos espaços da mobilidade. GEOgraphia, Niterói, RJ, v. 3, n. 6, p. 7-17, 2001.

MARANDOLA JR., E. Habitar em risco: mobilidade e vulnerabilidade na experiência metropolitana. São Paulo: Blucher, 2014.

Fenomenologia e pós-fenomenologia: alternâncias e projeções do fazer 
geográfico humanista na geografia contemporânea. Geograficidade, Niterói, RJ, v. 3, n. 2, p. 49-64, 2013.

Lugar enquanto circunstancialidade. In: MARANDOLA JR, E.; HOLZER, W.; OLIVEIRA, L. (Org.). Qual o espaço do lugar? Geografia, epistemologia, fenomenologia. São Paulo: Perspectiva, 2012. p. 227-248.

MASSEY, D. Um sentido global de lugar. In: ARANTES, O. (Org.). O espaço da diferença. Campinas: Papirus, 2010. p. 176-185.

Pelo espaço: uma nova política da espacialidade. Rio de Janeiro: Bertrand Brasil, 2000.

MELLO, J. O triunfo do lugar sobre o espaço. In: MARANDOLA JR., E.; HOLZER, W.; OLIVEIRA, L. (Org.). Qual o espaço do lugar? Geografia, epistemologia, fenomenologia. São Paulo: Perspectiva, 2012. p. 33-68.

. Explosões e estilhaços de centralidades no Rio de Janeiro. Espaço e Cultura, Rio de Janeiro, n. 1, p. 23-44, 1995.

O Rio de Janeiro dos compositores da música popular brasileira (1928-1991): uma introdução à geografia humanística. Dissertação (Mestrado em Geografia) - Instituto de Geociências, Universidade Federal do Rio de Janeiro, Rio de Janeiro, 1991.

. Geografia humanística: a perspectiva de experiência vivida e uma crítica radical ao positivismo. Revista Brasileira de Geografia, Rio de Janeiro, v. 52, n. 4, p. 91-115, 1990.

MERRIMAN, P. Mobility. In: KITCHIN, R.; THRIFT, N. (Ed.). International Encyclopedia of Human Geography. Amsterdam: Elsevier Science, 2009. v. 7. p. 134-143.

MOREIRA, R. Pensar e ser em geografia. São Paulo: Contexto, 2010.

OLIVEIRA, L. O sentido de lugar. In: MARANDOLA JR, E.; HOLZER, W.; OLIVEIRA, L. (Org.). Qual o espaço do lugar? Geografia, epistemologia, fenomenologia. São Paulo: Perspectiva, 2012. p. 3-16.

RELPH, E. Reflexões sobre a emergência, aspectos e essência de lugar. In: MARANDOLA JR., E.; HOLZER, W.; OLIVEIRA, L. (Org.). Qual o espaço do lugar? Geografia, epistemologia, fenomenologia. São Paulo: Perspectiva, 2012. p. 17-32.

. Sense of Place. In: HANSON, S. (Ed.). Ten Geographical Ideas that Have Changed the 
World. New Jersey: Rutgers University Press, 1997. p. 205-226.

. As bases fenomenológicas da geografia. Geografia, Rio Claro, SP, v. 4, n. 7, p. 1-25, 1979.

. Place and Placelessness. Londres: Pion, 1976.

ROSAS, G.; HOGAN, J. Ritmo e mobilidade cotidianos na experiência da metrópole. In: ENCONTRO DE GEÓGRAFOS DA AMÉRICA LATINA, 12., 2009 Montevideo. Anais... Montevideo, 2009.

SEAMON, D. Corpo-sujeito, rotinas espaço-temporais e danças-do-lugar. Geograficidade, NiteróiRJ, v. 3, n. 2, p. 4-18, 2013.

. A Geography of the Lifeworld: Movement, Rest, and Encounter. London: Croom Helm, 1979.

SHELLER, M. Mobility. Sociopedia.isa (Online), Madrid, jul. 2011. Disponível em: http://www. sagepub.net/isa/resources/pdf/Mobility.pdf. Acesso em: 12 fev. 2017.

; URRY, J. The new mobilities paradigm. Environment and Planning A, v. 38, p. 207-226, 2006.

TUAN, Y. Space and Place 2013. Geograficidade, Niterói, RJ, v. 4, n. 1, p. 4-13, 2014.

. Espaço e lugar: a perspectiva da experiência. Londrina: Eduel, 2013.

. Espaço, tempo, lugar: um arcabouço humanista. Geograficidade, Niterói, RJ, v. 1, n. 1, p. 4-15, 2011.

. Geografia humanística. In: CHRISTOFOLETTI, A. (Org.). Perspectivas da Geografia. São Paulo: Difel, 1985. p. 103-141.

. Ambiguidades nas atitudes para com o meio ambiente. Boletim Geográfico. Rio de Janeiro, v. 33 , n. 245 , p. $5-23,1975$ b.

. Place: An experiential perspective. Geographical Review, v. 65, n. 2, p. 151-165, 1975 a.

VIRILIO, P. Guerra pura. São Paulo: Página Aberta, 1984. 